\title{
Low-level Green and Red Laser Treatment of Shaochong (HT9)·Dadun (LR1) and Shaohai (HT3) -Yingu (KI10) Acupoints in a Rat Model of Focal Cerebral Ischemia
}

\author{
Chang-Su Na, Wang-In Kim, Ho-Sun Jang, and Dae-Hwan Youn \\ Department of Acupoint \& Meridian, Oriental Medical School, Dongshin University, Naju 520-714, Korea \\ Young-Min Moon \\ Department of Medical System Engineering, Gwangju Institute of Science and Technology, Gwangju 500-712, Korea \\ Sung-Ho Jeong \\ School of Mechatronics, Gwangju Institute of Science and Technology, Gwangju 500-712, Korea \\ Min-Woo Cheon ${ }^{\dagger}$ \\ Department of Health Administration, Dongshin University, Naju 520-714, Korea
}

Received February 12, 2015; Revised February 23, 2015; March 9, 2015

\begin{abstract}
Low level laser therapy (LLLT) has facilitated an improvement in acupuncture treatment. In this study, we stimulated Shaochong (HT9), Dadun (LR1), Shaohai (HT3), and Yingu (KI10) acupoints with pulsed laser diodes $532 \mathrm{~nm}$ [green laser] and $658 \mathrm{~nm}$ [red laser] in rats with induced middle cerebral artery occlusion(MCAO). The animals were divided into 6 groups: intact control; MCAO control without LLLT; LLLT with red laser at HT9-LR1 and HT3·KI10 (RR); LLLT with green laser at HT9.LR1 and HT3·KI10 (GG); LLLT with green laser at HT9·LR1 and red laser at HT3·KI10 (GR); and LLLT with red laser at HT9.LR1 and green laser at HT3·KI10 (RG). We evaluated the immunohistochemical changes in the hippocampal CA1 region, and complete blood count changes. Compared to the MCAO control group, the RG group showed a significant decrease in Bax and cytochrome c levels in the hippocampus, and a significant increase in hemoglobin level, hematocrit, total white blood cell, neutrophil, lymphocyte, monocyte, and erythrocyte counts.
\end{abstract}

Keywords: LLLT, MCAO, Acupoint, Focal brain ischemia, Reinforcement-reduction

\section{INTRODUCTION}

Low Level Laser Therapy (LLLT) has recently gained acceptance as irradiation of acupuncture point [1-3]. In acupuncture, acupoints are considered to be located along the meridians.

${ }^{\dagger}$ Author to whom all correspondence should be addressed:

E-mail: mwcheon@dsu.ac.kr

Copyright $@ 2015$ KIEEME. All rights reserved.

This is an open-access article distributed under the terms of the Creative Commons Atrtibution Non-Commercial
License (http://creativecommons.org/licenses/by-nc/3.0) which permits unrestricted noncommercial use,

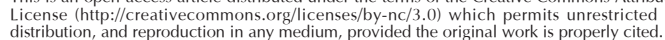

Stimulation of those points rebalances Qi and blood circulation, thereby preventing or even treating medical conditions [4]. The use of laser beams has helped increase the cure rate of acupuncture treatment $[5,6]$. Examples of laser acupuncture treatments vary and comprise of a wide range of different combinations of acupoints and laser wavelengths [7]. Siedentopf et al. [8] stimulated Zhiyin (BL67) with laser acupuncture, and detected activation of the visual association cortex by functional magnetic resonance imaging. Litscer et al. $[9,10]$ stimulated Dazhui (GV14) with $405 \mathrm{~nm}$ violet laser acupuncture, and observed increased cerebral blood flow using transcranial Doppler sonography. 
Fiore et al. [11] reported that high-intensity laser therapy is more effective than ultrasound short-term relief of low back pain. The advantages of laser acupuncture have also been reported for pediatric monosymptomatic enuretic symptoms [12], liver disease [13], endocrine disorders [14], neuropathic pain caused by damage to the tibial and sural nerves [15], blood pressure [16], and cell apoptosis [17].

In this study, we stimulated Shaochong (HT9), Dadun (LR1), Shaohai (HT3), and Yingu (KI10) acupoints with green (532 nm) and red $(658 \mathrm{~nm})$ laser diodes in rats with induced middle cerebral artery occlusion(MCAO).

\section{EXPERIMENTS}

\subsection{Laser equipment}

The low level laser system, which can simultaneously emit dual-wavelengths (532 and $658 \mathrm{~nm}$ ), was manufactured at the Laser Micro/Nano Fabrication Laboratory of Gwangju Institute of Science and Technology (GIST) for laser light stimulation at the Shaochong(HT9)·Dadun(LR1) and Shaohai(HT3).Yingu(KI10) acupoints on a rat model of focal cerebral ischemia. A schematic diagram of the low level laser is shown in Fig. 1. Three switching mode power supplies (SMPS) were used to supply electric power $(+5 \mathrm{~V},-5 \mathrm{~V},+15 \mathrm{~V}$, and $-15 \mathrm{~V})$ to the electronic parts and laser diode driver (LDD), with which the output power of the $532 \mathrm{~nm}$ (Green) and $658 \mathrm{~nm}$ (Red) lasers could be independently controlled by using a digital signal processing (DSP) Chip (TMS320F1812, Texas Instruments Inc.). The digital signal generated by the DSP was converted to an analog signal by using a digital analog converter (DAC) to control the LDD modules (WLD3343, Wavelength electronics Inc.) which maintains the laser diode current with high precision.

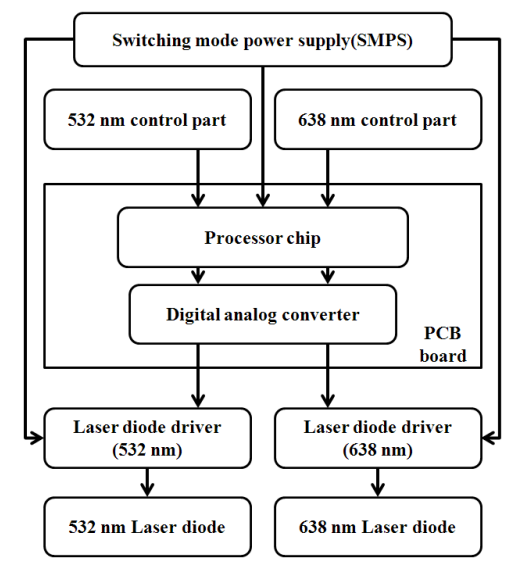

Fig. 1. A schematic diagram of the low level laser.

Table 1 shows the specifications of fiber-pigtailed laser diode. Maximum output powers of the laser diodes were $30 \mathrm{~mW}$ and 60 $\mathrm{mW}$ for the $532 \mathrm{~nm}$ and $638 \mathrm{~nm}$ wavelengths, respectively. The output power from each diode was split by half using a $1 \times 2$ multimode fiber coupler. Thus, the system had two output ports for each of the 532 and $658 \mathrm{~nm}$ wavelengths. In experiments, all four laser output ports were used at the repetition rate of $20 \mathrm{~Hz}$. The laser irradiation in experiments was carried out at $10 \mathrm{~mW}$ peak power for 3 minutes in pulse mode for both laser wavelengths.

\subsection{Experimental animal model}

Adult male Sprague-Dawley rats (Samtako Bio, Korea) weigh-
Table 1. The specifications of fiver-pigtailed laser diode.

\begin{tabular}{|c|c|c|c|}
\hline \multicolumn{2}{|c|}{ Specifications } & & $658 \mathrm{~nm}$ \\
\hline \multirow{4}{*}{$\begin{array}{c}\text { Optical } \\
\text { properties }\end{array}$} & CW output power & $30 \mathrm{~mW}$ & $60 \mathrm{~mW}$ \\
\hline & Wavelength & $532 \pm 0.5 \mathrm{~nm}$ & $658 \pm 4 \mathrm{~nm}$ \\
\hline & Mode quality & $<1.4$ & $<1.5$ \\
\hline & Power stability & $< \pm 5 \%$ & $<10 \%$ \\
\hline \multirow{4}{*}{$\begin{array}{l}\text { Electrical } \\
\text { properties }\end{array}$} & $\begin{array}{c}\text { Operating } \\
\text { voltage }\left(\mathrm{V}_{0}\right)\end{array}$ & $<2.3 \mathrm{~V}$ & $<3 \mathrm{~V}$ \\
\hline & $\begin{array}{l}\text { Threshold } \\
\text { current }\left(\mathrm{I}_{\mathrm{th}}\right)\end{array}$ & $200 \pm 20 \mathrm{~mA}$ & $60 \pm 5 \mathrm{~mA}$ \\
\hline & $\begin{array}{l}\text { Operating } \\
\text { current }\left(\mathrm{I}_{0}\right)\end{array}$ & $300 \pm 5 \mathrm{~mA}$ & $100 \pm 10 \mathrm{~mA}$ \\
\hline & $\begin{array}{c}\text { Maximum } \\
\text { current }\left(\mathrm{I}_{\max }\right)\end{array}$ & $600 \mathrm{~mA}$ & $150 \mathrm{~mA}$ \\
\hline \multirow{5}{*}{$\begin{array}{l}\text { Accessory } \\
\text { properties }\end{array}$} & Optical fiber type & Multimode & Multimode \\
\hline & $\begin{array}{l}\text { Core/cladding } \\
\text { diameter }\end{array}$ & $50 / 125 \mathrm{um}$ & $50 / 125 \mathrm{um}$ \\
\hline & $\begin{array}{c}\text { Numerical } \\
\text { aperture }\end{array}$ & 0.22 & 0.22 \\
\hline & $\begin{array}{c}\text { Transmission } \\
\text { loss }\end{array}$ & $0.3 \pm 0.05 \mathrm{~dB} / \mathrm{Km}$ & $0.3 \pm 0.05 \mathrm{~dB} / \mathrm{Km}$ \\
\hline & Connector type & FC/PC & FC/PC \\
\hline
\end{tabular}

Table 2. Experimental groups and interventions.

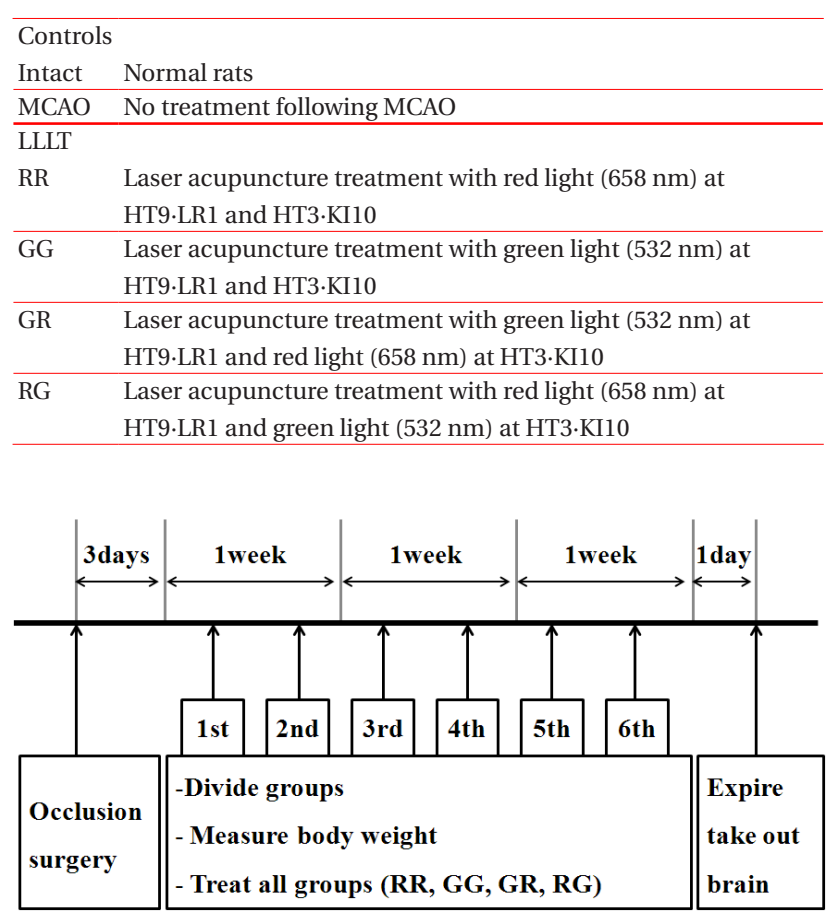

Fig. 2. Low level laser acupuncture treatment.

ing 200 250 g at the time of surgery were used. Animals were housed in a temperature-controlled room $\left(22 \pm 3^{\circ} \mathrm{C}\right)$ under a 12 hour light-dark cycle, with food (Dong A One, Korea) and water available ad libitum.

Occlusion of the middle cerebral artery by intraluminal filament insertion was performed as described previously [14]. Shaochong(HT9) is located at the 5th distal phalanx of the forelimb to the internal corner of the fingernail. Dadun(LR1) is located at the 1st distal phalanx of the hind limb to the lateral corner of the toenail. Shaohai(HT3) is located at the medial epicondyle of the humerus and the anterior towards anteromedial aspect of 
the elbow. Yingu(KI10) is located at the posteromedial aspect of the knee, which targets all body segments.

Animals were divided into 6 experiment groups. Three days after middle cerebral artery occlusion(MCAO), laser acupuncture treatment was conducted twice a week for 3 weeks in all groups except the intact control group. The left and right acupoints were used alternatel throughout the treatment period. Before acupoint stimulation, anesthesia was maintained with isoflurane (Terrell; Minrad Inc., USA) on an anesthesia ventilator.

The customized laser equipment descried in Section 2.2. and a needle of $200 \mu \mathrm{m}$ in diameter were used. The wavelength of the red and green laser diode was set at $658 \mathrm{~nm}$ and $532 \mathrm{~nm}$, respectively. The frequency of the red and green laser was set at $20 \mathrm{~Hz}$. The lasers were operated to deliver $10 \mathrm{~mW}$ per 3 minutes in pulse waves.

\section{RESULTS AND DISCUSSION}

\subsection{Dual-wavelength laser system}

In our work, an optical fiber based acupuncture needle was also developed, in order to directly deliver the laser light to acupoints without loss; this is because an irradiation on the skin surface results in a significant loss of laser energy by tissues preventing the acupoints receving a proper laser light stimulation [18].

Figure 3 shows a schematic and photograph of the completed acupuncture needle. A thin stainless steel tube (outside diameter $=300 \mathrm{~m}$ ) with a shape tip was used as the needle, in which an optical fiber was inserted and fixed with a glue. The end of the inserted optical fiber was cut flat by a fiber cleaver and positioned close to the needle tip for minimum loss of laser light. The laser power emitted from the completed optical fiber acupuncture needle was measured with a power meter (PM100D, Thorlabs). To check the pulse shape of actual laser output, a small portion of the emitted laser output was collected and converted to electrical signal by using a photodetector (PD, DET39A/M, Thorlabs) and compared with the DAC output signal. The DAC and PD electrical signals for comparison were measured with a digital phosphor oscilloscope (TDS5054B, Tekronix) at the same time.

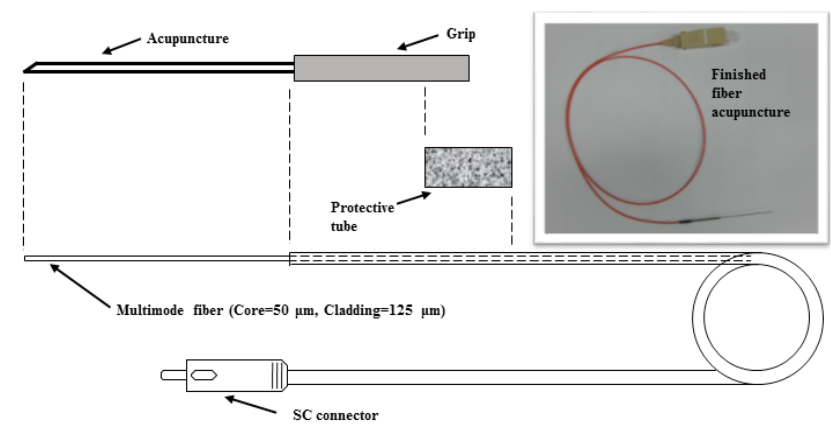

Fig. 3. A schematic and photograph of the completed acupuncture needle.

Figure 4 shows the output signals from the DAC and PD for the $532 \mathrm{~nm}$ laser. The repetition rate of the $532 \mathrm{~nm}$ output signal from the DAC was found to be identical to the PD signal at 20 $\mathrm{Hz}$, and the maximum value of two signals occurred at almost the same location. These results confirm that the input signal was accurately converted by the DAC producing the same laser output shape in time. When DAC signal reached over $0.15 \mathrm{mV}$, laser output was started. The shape of laser output was shown as pulse mode with $0.013 \mathrm{~ms}$ of pulse duration. Furthermore, the

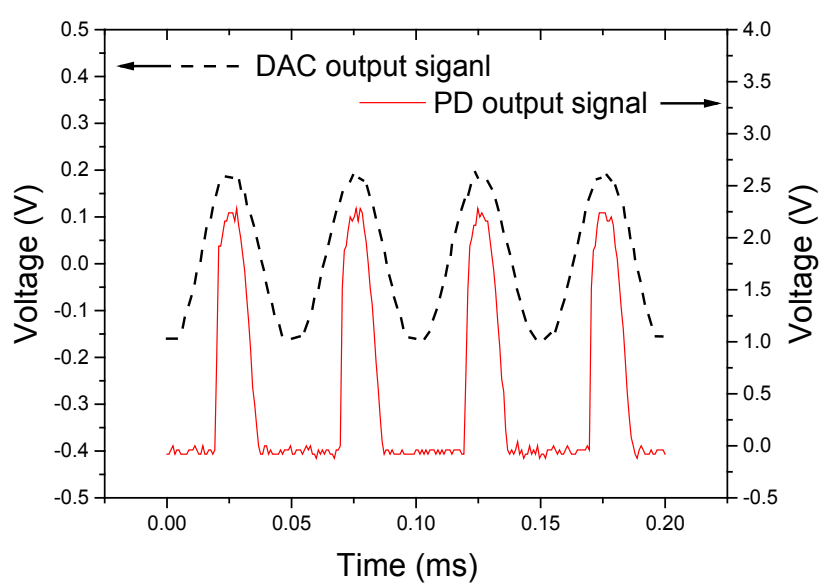

Fig. 4. The output signals from the DAC and PD for the $532 \mathrm{~nm}$ laser.

laser output was shown with high reproducibility with regard to intensity, repetition rate, and pulse duration, as shown in Fig. 4. Thus, in our work, the precise photonic stimulations from manufactured system based on digital signal processing were used.

\subsection{Low level laser acupuncture treatment}

The number of cresyl violet-stained neural cells, an indicator of neural injury, was significantly lower in the MCAO control group compared to the intact control group $(\mathrm{P}<0.01)$; and LLLT had no effect on cresyl violet-stained neural cells. The number of ChAT-stained neural cells, an indicator of neural injury, was significantly lower in the MCAO control group compared to the intact control group $(\mathrm{P}<0.01)$. LLLT resulted in a small increase in the number of ChAT-stained neural cells, but the difference was not statistically significant

Bax levels in the hippocampus of MCAO rats were significantly higher than those in the intact controls $(\mathrm{P}<0.01)$. The RG group showed a significant decrease in Bax level $(\mathrm{P}<0.01)$ compared to the MCAO control group. There were no statistically significant differences in Bcl-2 levels among the groups. Bax/Bcl-2 ratio in the hippocampus of MCAO rats was significantly higher than that in the intact controls $(P<0.01)$. RR, GG, GR, and RG groups showed significant reduction $(\mathrm{P}<0.05, \mathrm{P}<0.01)$ compared to the MCAO control group. Although cytochrome c levels in the hippocampus of MCAO rats were only slightly lower than those in intact controls, the GG, GR, and RG groups had significantly lower cytochrome $\mathrm{c}$ levels $(\mathrm{P}<0.05, \mathrm{P}<0.01)$ than the MCAO control group. Data were compared using Student t-test and Mann Whitney U-test (SPSS for Window; SPSS, USA). Results are expressed as the mean \pm standard error (SE), and differences were considered statistically significant at $\mathrm{P}<0.05$.

Table 3. Cresyl violet-stained and ChAT-stained neural cells in the hippocampus of control and LLLT treated rats.

\begin{tabular}{ccc}
\hline Group & $\begin{array}{c}\text { Cresyl violet stained } \\
\text { neural activity }\end{array}$ & ChAT neural activity \\
\hline Controls & $38.5 \pm 1.5$ & $12.8 \pm 1.8$ \\
Intact & $29.3 \pm 2.4^{\# \#}$ & $4.5 \pm 1.7^{\# \#}$ \\
MCAO & $29.7 \pm 1.6$ & $5.3 \pm 1.2$ \\
LLLT & $30.0 \pm 2.5$ & $6.0 \pm 2.0$ \\
RR & $26.5 \pm 2.3$ & $5.2 \pm 1.4$ \\
GG & $31.8 \pm 1.4$ & $6.7 \pm 1.5$ \\
GR & ${ }^{\#} \mathrm{P}<0.01$ compared with intact control. \\
RG
\end{tabular}


Table 4. Bax and Bcl-2 levels, Bax/Bcl-2 ratio and cytochrome $\mathrm{c}$ in the hippocampus of control and LLLT-treated rats.

\begin{tabular}{|c|c|c|c|c|}
\hline Group & Bax level & Bcl-2 level & Bax/Bcl-2 ratio & Cytochrome C \\
\hline \multicolumn{5}{|l|}{ Controls } \\
\hline Intact & $142.3 \pm 2.7$ & $137.2 \pm 3.4$ & $1.04 \pm 0.01$ & $170.9 \pm 3.7$ \\
\hline MCAO & $149.9 \pm 5.2$ & $127.3 \pm 4.1$ & $1.18 \pm 0.03^{\# \#}$ & $165.2 \pm 1.1$ \\
\hline \multicolumn{5}{|l|}{ LLLT } \\
\hline $\mathrm{RR}$ & $137.1 \pm 4.0$ & $127.7 \pm 4.3$ & $1.07 \pm 0.02^{*}$ & $168.7 \pm 4.1$ \\
\hline GG & $142.6 \pm 4.9$ & $132.2 \pm 4.3$ & $1.08 \pm 0.02^{* s}$ & $150.4 \pm 1.3^{* s}$ \\
\hline GR & $141.9 \pm 5.7$ & $132.0 \pm 3.7$ & $1.07 \pm 0.02^{* s}$ & $131.8 \pm 2.0^{* z}$ \\
\hline RG & $113.3 \pm 5.6^{* *}$ & $132.2 \pm 3.6$ & $0.87 \pm 0.02^{* s}$ & $157.1 \pm 2.9^{*}$ \\
\hline & & & \multicolumn{2}{|c|}{$\begin{array}{l}{ }^{*} \mathrm{P}<0.05, \mathrm{P}<0.01 \text { compared with the MCAO control. } \\
{ }^{s *} \mathrm{P}<0.01 \text { compared with MCAO control. } \\
{ }^{\# \#} \mathrm{P}<0.01 \text { compared with intact control }\end{array}$} \\
\hline
\end{tabular}

We found that LLLT significantly decreased apoptosis in the hippocampus. However, no significant differences were found in the number of injured neural cells in that brain area using a known indicator of neural injury, cresyl violet [18], or ChAT. The most effective combination could be red laser for supplementation and green laser for draining, which is in agreement with the work by Yoon et al. [19]. In the MCAO model, apoptosis within 5 to 7 days after induction of ischemia $[20,21]$. Bax, a factor that controls neural cell apoptosis, activates Pro-ICE- and caspasepromoting apoptosis [22]. contrast, Bcl-2 contributes to nerve regeneration by inhibiting apoptosis [23]. It is known that Bcl-2 activity is affected by Bax [23].

In our study, the Bax/Bcl-2 ratio was significantly lower in the RR, GG, GR, and RG groups compared to the MCAO control group. The greatest change was observed in the RG group, which again suggests that the combination of red and green lasers is effective for inhibiting apoptosis in the brain. Cytochrome c promotes Bax, and upon the release of cytochrome $\mathrm{c}$ to the cytoplasm, the protein binds apoptotic protease activating factor-1 (Apaf-1) and procaspase-9.

These complexes activate caspase- 3 an executer enzyme, and the apoptotic cascade is initiated [24]. Lee et al. [25] reported rapid cell apoptosis following microinjection of cytochrome $\mathrm{c}$ in cells.

Cytochrome c level were significantly lower in GG, GR, and RG groups than in the MCAO control group, suggesting that green light inhibits cytochrome c-induced apoptosis.

\section{CONCLUSIONS}

In this study, we stimulated Shaochong(HT9), Dadun(LR1), Shaohai(HT3), and Yingu(KI10) acupoints with green and red laser diodes in rats, which induced MCAO.

To this end, this paper developed Dual-wavelength Laser System. Dual-wavelength Laser System was designed and produced so that RED LD of $658 \mathrm{~nm}$ wavelength and Green LD of $532 \mathrm{~nm}$ wavelength can be oscillated. In the case of Output power, Red LD was $60 \mathrm{~mW}$ and Green LD was $30 \mathrm{~mW}$ in CW mode. An experiment was carried out for middle cerebral artery infarctioninduced experimental animals, by mounting developed Dualwavelength Laser System on a needle. As a result, in the changes in Cresyl violet and ChAT stained neural activity of Hippocampus, all of RR group, GG group, GR group, and RG group showed a similar level compared to MCAO control. In the effect of Hippocampus on bax level, RG group showed a significant decrease compared to MCAO control. In the effect of Hippocampus on bax level/bcl-2 ratio, RR group, GG group, GR group, and RG group showed a significant reduction compared to MCAO control. In the effect of Hippocampus on cytochrome c level, GG group, GR group, and RG group showed a significant decrease compared to

\section{MCAO control.}

In summary, laser acupuncture with red light $(658 \mathrm{~nm})$ at HT9.LR1 and green light (532 $\mathrm{nm})$ at HT3.KI10 is a promising treatment that could serve as an alternative to conventional acupuncture for ischemia-induced conditions.

\section{ACKNOWLEDGMENTS}

This work was supported by a grant of the Dong-shin University and the Ministry of Health and Welfare, Republic of Korea.

\section{REFERENCES}

[1] T. S. Wei, D. H. Youn, Y. C. Youn, and C. S. Na, J. Acupu. (Korean), 22, 9 (2005).

[2] W. I. Kim, D. H. Youn, C. H. Choi, and C. S. Na, J. Acupu. (Korean), 29, 131 (2012).

[3] J. A. Lim, W. S. Chae, S. H. Lee, S. H. Jeong, D. H. Youn, and C. S. Na, J. Acupu. (Korean), 28, 37 (2011).

[4] W. S. Chae, Introduction to Oriental Medicine (Daesung Publishing Inc., Seoul, 1997) p. 330.

[5] G. D. Baxter, C. Bleakley, and S. McDonough, J. Acupunct. Meridian Stud., 1, 65 (2008). [DOI: http://dx.doi.org/10.1016/ S2005-2901(09)60026-1]

[6] G. Litscher, Evid. Based Complement Alternat. Med., 2013, 1 (2013).

[7] C. H. Choi, K. S. Jang, C. S. Na, and C. H. So, Kor. J. Orient. Med. Phys. Patho., 15, 125 (2001).

[8] C. M. Siedentopf, S. M. Golaszewski, F. M. Mottaghy, C. C. Ruff, S. Felber, and A. Schlager, Neurosci. Lett., 327, 53 (2002). [DOI: http://dx.doi.org/10.1016/S0304-3940(02)00383-X].

[9] G. Litscher, T. Huang, L. Wang, and W. Zhang, J. Acupunct. Meridian Stud., 3, 255 (2010). [DOI: http://dx.doi.org/10.1016/ S2005-2901(10)60045-3].

[10] G. Litscher, L. Wang, T. Huang, and W. Zhang, J. Acupunct. Meridian Stud., 4, 164 (2011). [DOI: http://dx.doi.org/10.1016/ j.jams.2011.09.003].

[11] P. Fiore, F. Panza, G. Cassatella, A. Russo, V. Frisardi, V. Solfrizzi, M. Ranieri, L. Di Teo, and A. Santamato, Eur. J. Phys. Rehabil. Med., 47, 367 (2011).

[12] M. I. Karaman, O. Koca, E. V. Küçük, M. Öztürk, M. Güneş, and C. Kaya, J. Urol., 185, 1852 (2011). [DOI: http://dx.doi. org/10.1016/j.juro.2010.12.071].

[13] Y. S. Choi, M. S. Oh, T. W. Song, and C. W. Lee, J. Orient. Rehab. Med., 7, 78 (1997).

[14] Y. S. Zhang, Y. X. Xu, C. S. Chen, G. Z. Chen, Z. X. Weng, and Y. Yao, Laser Surg., 29, 271 (2011). [DOI: http://dx.doi. org/10.1089/pho.2010.2763]. .

[15] Y. S. Kim, MS. Dissertation (Dongshin University Graduate 
School, Naju, Korea, 2011).

[16] C. S. Na, D. H. Youn, C. H. Choi, S. H. Lee, G. H. Oh, and S. H. Jeong, J. Acupu. (Korean), 25, 199 (2008).

[17] S. O. Kim, Ph.D. Dissertation (Dongshin University Graduate School, Naju, Korea, 2009).

[18] M. Haitao W. Qingguo, X. Qian, L. Fangzheng, and C. Dongan, Proceedings of the International Workshop on Photonics and Imaging in Biology and Medicine 2002 (SPIE 4536, 12 April). [DOI: http://dx.doi.org/10.1117/12.462546].

[19] J. Y. Youn, Y. S. Kim, D. H. Youn, S. H. Lee, G. H. Oh, S. H. Jeong, and C. S. Na, J. Acupu.(Korean), 27, 125 (2010).
[20] L. Zhao, Y. Wang, N. Sun, X. Liu, L. Li, and J. Shi, Life Sci., 81, 211 (2007). [DOI: http://dx.doi.org/10.1016/j.lfs.2007.08.034].

[21] A. Buchan and W. A. Pulsinelli, J. Neurosci., 10, 311 (1990).

[22] J. M. Adams and S. Cory, Trends Biochem. Sci., 26, 61 (2001). [DOI: http://dx.doi.org/10.1016/S0968-0004(00)01740-0].

[23] Y. B. Ouyang and R. G. Giffard, Cell Calcium., 36, 303 (2004). [DOI: http://dx.doi.org/10.1016/j.ceca.2004.02.015].

[24] Y. Liu, L. Chen, X. Xu, E. Vicaut, and R. Sercombe, BMC Physiol., 9, 17 (2009). [DOI: http://dx.doi.org/10.1186/1472-6793-9-17].

[25] M. S. Lee and G. Kang, J. Pathol., 36, 1 (2002). 